\title{
PENGARUH KONSUMSI TABLET KALSIUM TERHADAP PERUBAHAN TEKANAN DARAH PADA IBU HAMIL RESIKO TINGGI HIPERTENSI DALAM KEHAMILAN DIWILAYAH KERJA PUSKESMAS PAYALOMBANG TEBING TINGGI
}

\author{
DAMAYANTI ${ }^{1}$, FITRIANI ${ }^{2}$, DWI HANDAYANI ${ }^{3}$, DIAH EVAWANNA \\ ANUHGERA ${ }^{4}$, NOVITA GINTING ${ }^{5}$ \\ 1,2,3,4,5 INSTITUT KESEHATAN MEDISTRA LUBUK PAKAM \\ JLN SUDIRMAN NO. 38 LUPUK PAKAM DELI SERDANG SUMATERA UTARA \\ e-mail : dama77.yanti@gmail.com
}

DOI: $10.35451 / j k k . v 3 i 1.510$

\begin{abstract}
Calcium is an important supplement that is useful to supply calcium needs of pregnant women. Calcium is given by midwife special health workers to all pregnant women to support the health of mothers and babies. This free calcium tablet is often forgotten and avoided by health workers whether or not consumed properly by pregnant women.

This study aims to see if the influence of calcium tablets on the decrease in blood pressure of pregnant women who have one of the criteria of high risk of hypertension, including primigravida, obesity, pregnancy history with hypertension or family with a history of hypertension, extreme age of pregnant women and twin pregnancies.

Research place in Payalombang Public Health Center in Payalombang Subdistrict, Tebing Tinggi City with quasy experiment method and prospective cohort. The study subjects consisted of 19 mothers who were given calcium with help and 20 pregnant women who were not given calcium, according to the inclusion and exclusion criteria. Data characteristics used using a questionnaire. To assess the outcome using an observation sheet and a calibrated blood pressure gauge) get it twice before and after the intervention. Data analysis using, Paired T Test, Independent T-Mann-Whitney U Test.

The results of the study address, a sample study of changes in systole ( $p=$ $0.032)$ and diastole $(p=0.015)$ significant $(p>0.05)$ value even though it means the difference between before and the difference rates.

Conclusion: Calcium tablets have a significant effect on hypertension of pregnant women
\end{abstract}

Keywords: Calcium, blood pressure, high risk of hypertension

\section{Pendahuluan}

Hipertensi dalam kehamilan merupakan suatu kelainan yang memiliki beragam teori yang dikemukakan, namun belum ada satupun dari teori tersebut secara pasti mengungkapkan patofisiologi hipertensi dalam kehamilan yang sebenarnya (Cunningham et al., 2012). Hipertensi dalam kehamilan yaitu salah satu penyebab utama mortalitas dan morbiditas wanita hamil $5-10 \%$ dari semua kehamilan diseluruh dunia (Ayele, 2016). 
Faktor terjadinya hipertensi yaitu sebagian besar dari kelompok umur 20-35 tahun sebesar $64,4 \%$, ibu yang memiliki paritas primigravida sebesar $69,5 \%$ dan pada ibu yang memiliki kehamilan > 4 sebesar 76,3\%, sehingga ibu hamil yang memiliki karakteristik tersebut memiliki resiko mengalami hipertensi dalam

termasik preeklamsi dan eklamsi (Desi et al., 2017). Secara global, 80\% penyebab kematian ibu secara langsung, yaitu disebabkan karena terjadi perdarahan (25\%) biasanya perdarahan pasca persalinan, hipertensi pada ibu hamil (12\%), partus macet $(8 \%)$, aborsi $(13 \%)$ dan karena sebab lain (7\%) (Desi et al., 2017).

Pada saat hamilan terjadi perubahan kebutuhan baik fisik maupun psikologis. Kalsium merupakan salah satu mineral yang sangat dibutuhkan pada berbagai proses, seperti transportasi antar membran sel, aktivasi dan inhibisi beberapa enzim, regulasi metabolik intraseluler, sekresi dan aktivasi hormon, proses pembekuan darah, kontraktilitas otot

\section{METODE}

Jenis penelitian kuasi eksperimen dengan menggunakan pendekatan kohort prospektif yang bertujuan untuk mengetahui bagaimana pengaruh pemberian tablet kalsium pada ibu hamil dengan resiko tinggi hipertensi. Dimana pada kelompok ini dibagi

\section{HASIL}

Tabel 4.1 Distribusi karateristik responden

\begin{tabular}{lcccc}
\hline \multirow{2}{*}{ Variabel } & \multicolumn{2}{c}{ K 1 } & \multicolumn{2}{c}{ K 2 } \\
\cline { 2 - 5 } & $\mathrm{n}$ & $(\%)$ & $\mathrm{n}$ & $(\%)$ \\
\hline Usia & & & & \\
Normal & 14 & 73,7 & 15 & 75 \\
Resiko & 5 & 26,3 & 5 & 25 \\
Tinggi & & & & \\
IMT & & & &
\end{tabular}

dan konduksi sistem syaraf (Apriani et al., 2018).

Asupan kalsium rendah menyebabkan peningkatan tekanan darah tinggi dengan merangsang pelepasan hormone paratiroid dan renin yang mengarah terjadinya peningkatan konsentrasi kalsium intra seluler dalam vaskuler sel otot polos dan mengakibatkan vasokonstriksi. Peranan suplemen kalsium dalam menurunkan gangguan hipertensi kehamilan dengan menurunkan pelepasan kalsium paratiroid dan konsentrasi kalsium intraseluler, akhirnya terjadi penurunan kontraksi otot polos dan peningkatan vasodilatasi.

Berdasarkan rekomendasi dari WHO, Indonesia melalui Kementrian Kesehatan memberikan suplementasi kalsium untuk pencegahan preeklamsia bagi semua ibu hamil terutama yang memiliki resiko tinggi terjadinya preeklamsia dengan asupan kalsium rendah dengan dosis 1,5-2 gram per hari (Dahniarti, Idris and Am, 2018).

menjadi 2 kelompok: kelompok 1 merupakan kelompok ibu hamil yang diberikan tablet kalsium dengan pengawasan (intervensi) dan kelompok 2 merupakan kelompok ibu hamil yang tidak diberikan perlakuan apapun (kontrol).

$\begin{array}{lcccc}\begin{array}{l}\text { Normal } \\ (\leq 28)\end{array} & 15 & 78,9 & 15 & 75 \\ \begin{array}{l}\text { Resiko } \\ \text { Tinggi (>28) }\end{array} & 4 & 21,4 & 5 & 25 \\ \begin{array}{l}\text { Riwayat } \\ \text { Penyakit }\end{array} & & & & \\ \begin{array}{l}\text { Normal } \\ \text { Resiko }\end{array} & 17 & 89.5 & 20 & 100 \\ \begin{array}{l}\text { Tinggi } \\ \text { Kehamilan } \\ \text { Kembar }\end{array} & 2 & 10,5 & 0 & 0 \\ & & & & \\ \end{array}$


Normal

Resiko

$\begin{array}{llll}18 & 94,7 & 20 & 100\end{array}$

Tinggi

\section{Gravida}

Normal (>1) $5 \quad 26,3 \quad 7 \quad 35$

Resiko

$\begin{array}{llll}14 & 73,7 & 13 & 65\end{array}$

Tinggi (1)

\section{Pendidikan}

$\begin{array}{lllll}\text { Pendidikan } & 3 & 15,8 & 5 & 25\end{array}$

Tinggi

$\begin{array}{lllll}\text { Pendidikan } & 16 & 84,2 & 15 & 75\end{array}$

Rendah

Pekerjaan

\begin{tabular}{lcccc} 
Bekerja & 8 & 42,1 & 14 & 70 \\
IRT & 11 & 57,9 & 6 & 30 \\
\hline
\end{tabular}

Pada tabel 4.1 pada data karakteristik responden yang terdistribusi yaitu pada kelompok kontrol lebih besar kelompok tidak beresiko 15 orang sementara intervensi adalah 14 orang. Kemudian ibu yang memiliki indeks masa tubuh yang mungkin akan menimbulkan resiko hipertensi yaitu 4 orang pada kelompok intervensi dan 5 pada kelompok kontrol. Ibu yang memiliki riwayat penyakit terdapat pada kelompok intervensi sejumlah 2 orang.

Pada ibu primigarvida terdapat 14 orang pada kelompok intervensi dan 13 orang pada kelompok kontrol. Pada kelompok intervensi maupun kontrol mayoritas berpendidikan rendah, sementara ibu yang bekerja terdapat pada kelompok kontrol.

Tabel 4.2 Distribusi Perubahan TD pada responden

\begin{tabular}{lcccc}
\hline \multirow{2}{*}{ Variabel } & \multicolumn{2}{c}{ K1 } & \multicolumn{2}{c}{ K2 } \\
\cline { 2 - 5 } & $\mathrm{N}$ & $(\%)$ & $\mathrm{n}$ & $(\%)$ \\
\hline Sistole & & & & \\
Menurun & 15 & 78,95 & 9 & 55 \\
$\begin{array}{l}\text { Tidak } \\
\text { Menurun }\end{array}$ & 4 & 21,05 & 11 & 45 \\
$\begin{array}{l}\text { Diastole } \\
\text { Menurun }\end{array}$ & 15 & 78,95 & 8 & 40 \\
$\begin{array}{l}\text { Tidak } \\
\text { Menurun }\end{array}$ & 4 & 21,05 & 12 & 25 \\
\hline
\end{tabular}

\begin{tabular}{lllll}
\hline Total & 19 & 100 & 20 & 100 \\
\hline
\end{tabular}

Pada table 4.2 terlihat bahwa pada kelompok intervensi lebih banyak terdapat ibu hamil yang mengalami penurunan systole (15 orang) dan diastole (15 orang ) dibandingkan dengan kelompok control dimana ibu hamil yang mengalami penurunan systole ( 9 orang) dan diastole (8 orang). Kalsium

Tabel 4.3 Pengaruh Tablet terhadap systole Ibu Hamil Resiko Hipertensi

\begin{tabular}{lcccc}
\hline $\begin{array}{l}\text { Variabel } \\
\mathrm{mmHg}\end{array}$ & $\mathrm{n}$ & $\times$ & $p$ & \multicolumn{2}{c}{$95 \% \mathrm{CI}$} \\
\cline { 4 - 5 } & & & & Min Max \\
\hline $\begin{array}{l}\text { K1 } \\
\text { Sistole }\end{array}$ & 19 & 4,21 & & \\
K2 & 20 & 4 & 0,03 & 0,15 \\
Sistole & & & & $(-0,09-0,7)$ \\
\hline
\end{tabular}

Tabel 4.4 Pengaruh Pemberian Tablet Kalsium terhadap perubahan diastole Pada Dua Kelompok Ibu Hamil Resiko Hipertensi

\begin{tabular}{lcccc}
\hline $\begin{array}{l}\text { Variabel } \\
\mathrm{mmHg}\end{array}$ & $\mathrm{n}$ & $\times$ & $p$ & \multicolumn{2}{c}{$95 \% \mathrm{CI}$} \\
\cline { 5 - 5 } & & & & Minl Max \\
\hline $\begin{array}{l}\text { K1 } \\
\text { Diastole }\end{array}$ & 19 & 1,58 & & \\
$\begin{array}{l}\text { K2 } \\
\text { Diastole }\end{array}$ & 20 & 3 & 0,015 & $\begin{array}{c}0,15 \\
(0,09-0,7)\end{array}$ \\
\hline
\end{tabular}

Tabel 4.3 menunjukkan ada perbedaan perubahan nilai systole pada kelompok intervensi dan kelompok kontrol yang telah dilakukan uji normalitas menggunakan uji Shapiro-Wilk. Pada hasil Independent $T$ Test pada nilai perubahan diastole memiliki nilai mean lebih rendah $(1,58$ vs 3$)$ tetapi berdasarkan nilai $p=0,015$ menunjukan bahwa terdapat perbedaan perubahan nilai diastole antara kedua kelompok.

\section{PEMBAHASAN}


Asupan kalsium adalah jumlah kalsium yang bersumber dari makanan dan dikonsumsi dalam sehari. Asupan kalsium anjuran ialah $1200 \mathrm{mg} / \mathrm{hari}$ untuk ibu hamil berumur 30-35 tahun dan $1300 \mathrm{mg} /$ hari untuk ibu hamil berumur 20-29 tahun. Kebutuhan kalsium meningkat pada saat hamil karena digunakan untuk mengganti cadangan kalsium ibu guna pembentukkan jaringan baru pada janin. Ibu hamil yang mengonsumsi kalsium yang cukup akan mengurangi ibu untuk mempunyai risiko 4 kali mengalami hipertensi pada kehamilan dibandingkan responden yang tidak mengonsumsi kalsium dalam jumlah yang cukup. Peranan kalsium dalam hipertensi kehamilan sangat penting, karena kekurangan kalsium dalam diet dapat memicu terjadinya hipertensi. Kalsium berfungsi untuk mempertahankan konsentrasi dalam darah pada aktivitas kontraksi otot. Kontraksi otot pembuluh darah sangat penting karena dapat mempertahankan tekanan darah.

Kalsium yang diekskresikan oleh ginjal meningkat pada ibu hamil dibandingkan pada wanita yang tidak hamil dari $100-250 \mathrm{mg} /$ hari menjadi 350-620 mg/hari selama kehamilan dalam keadaan normal. Ekskresi kalsium meningkat melalui urin selama hamil dari trimester satu dan paling tinggi terjadi di trimester ketiga. Hal ini merupakan hal yang fisiologis terjadi yang disebabkan penyerapan kalsium oleh usus ibu meningkat. Wanita dengan hipertensi kehamilan memiliki ekskresi urine yang jauh lebih sedikit mengandung kalsium dibandingkan dengan wanita normotensi, meskipun penurunanya tidak sejauh yang terjadi pada ibu hamil pre-eklampsia. Wanita denganhipertensi kronis juga cenderung memiliki ekskresi urin kalsium yang lebih rendah daripada wanita normotensive.(Palareti et al., 2016)

University of London adalah universitas yang pertamakali mengamati bahwa kalsium diperlukan untuk kontraksi otot dan sekarang telah diketahui bahwa calcium merupakan komponen penting sebagai penghubung jaringan kontraktil untuk menstimulus kontraksi jaringan seluler untuk sekresi hormonal dan semua jaringan yang merespon berbagai rangsangan fisiologis dan berkontribusi pada homeostasis tekanan darah. Pengamatan oleh McCarron et al dan Strazzullo et al mengamati bahwa ginja berpotensi terlihat mengekskresi kalsium dan natrium pada orang yang mengalami hipertensi(Resnick, 1998; Fantin et al., 2019).

Berdasarkan hasil penelitian diketahui subjek penelitian yang mengkonsumsi asupan kalsium pada kelompok intervensi mengalami penurunan baik pada systole $(p=0,032)$ dan diastole $(p=0,015)$. Sehingga dari hasil penelitian tersebut dapat dilihat bahwa ada perbedaannya antara ibu hamil yang memiliki asupan kalsium kurang dan ibu hamil yang memiliki asupan kalsium hal yang sama juga diperlihatkan oleh penelitian yang dilakukan Tanzil, 2013 (Tanzil, 2013).

Tetapi tidak sama dengan yang ditunjukan oleh perbedaan nilai systole dan diastole sebelum dan sesudah pemberian tablet kalsium $(p>0,05)$. Walaupun nilai mean diantara kedua kelompok untuk systole dan diastole menunjukkan perbedaan, hasil yang sama di temukan pada penelitian yang dilakukan (Schoenaker, SoedamahMuthu and Mishra, 2014).

Rendahnya asupan kalsium pada wanita hamil mengakibatkan peningkatan hormon paratiroid (PTH), dimana akan mengakibatkan kalsium intraseluler meningkat melalui permeabilitas membrane sel terhadap 
kalsium. Hal tersebut mengakibatkan kalsium dari mitokondria lepas ke sitosol. Peningkatan kadar kalsium intraseluler menyebabkan otot polos pembuluh darah mudah terangsang untuk vasokonstriksi yang mengakibatkan tekanan darah meningkat (Tesfaye, Gudeta and Regassa; Parikh et al., 2017).

Dari hasil penelitian ini, adanya hubungan asupan kalsium dengan pencegahan hipertensi dalam kehamilan antara kelompok intervensi dan kontrol, tetapi hal yang berbeda ditemukan pada nilai systole dan diastole sebelum dan sesudah pada kedua kelompok, yang mungkin disebabkan dapat disebabkan karena beberapa hal, salah satunya yaitu perhitungan sampel minimal. Jumlah sampel yang digunakan dalam penelitian ini masih kurang, sehingga dalam penelitian ini prevalensi asupan kalsium cukup yang didapat sedikit, serta waktu pemberian tablet kalsium yang cukup pendek sehingga kurang menunjukan perubahan tekanan darah yang cukup signifikan antara sebelum dan sesudah intervensi (Resnick, 1998)

$$
\text { Pada peningkatan asupan }
$$
kalsium mengurangi tekanan darah sistolik dan diastolic pada orang-orang yang normotensife. Pada seluruh responden tidak ditemukan satupun masalah terkait pemberian suplemen kalsium dengan dosis 1000-1500 mg/hari (Gabriela Cormick, Agustín Ciapponi and María Luisa Caerata, 2015). Pemberian suplementasi pada pertengahan masa kehamilan mengurangi terjadinya maslah serius akibat dari preeklampsi, tetapi tidak keseluruhan masalah yg diakibatkan oleh preeclampsia. Sehingga mungkin penting untuk dilakukan penelitian berikutnya tentang pemberian lebih awal suplementasi kalsium pada ibu hamil (Hofmeyr et al., 2019). Pemberian kalsium dosis rendah pada awal kehamilan juga sangat bermanfaat terhadap resiko dari kasus patologi yang mungkin ada pada ibu hamil. Alasan pemberian kalsium lebih awal juga didasarkan pada teori pembentukan dan perkembangan plasenta yang berkembang hingga pertengahan paruh masa hamil (Hofmeyr, Belizán and Von Dadelszen, 2014)

Hormon yang dihasilkan tubuh juga dapat mempengaruhi peningkatan tekanan darah pada tubuh seperti hormone steroid yang dihasilkan oleh glomerulus di korteks adrenal. Akibat dari pengaruh hormone aldosterone terjadi peningkatan permeabilitas menbran untuk menyaring sodium, penyerapan kembali sodium dan air meningkatkan cairan ekstraseluler sehingga kardiak output juga meningkat dan terjadi peningkatan tekanan darah (Villa-Etchegoyen et al., 2019). Pada ibu primigravida atau hamil pertama kali, tubuh akan belajar untuk beradaptasi terhadap perubahan dari seluruh fungsi faal tubuh. Tubuh akan mengalami perubahan kondisi agar dapat menjaga homestasis tubuh. Hal ini memungkinkan pada ibu prmigravida memiliki resiko tinggi terjadi masalah seperti hipertensi (Kyozuka et al., 2020).

Kebutuhan kalsium sangat penting bagi tubuh, karena kalsium memiliki peran vital yang menjamin proses tubuh berjalan dalam keadaan yang seimbang, termasuk mengkompensasi perubahan fisiologis pada ibu hamil. Tetapi perubahan fisiologis ini dapat menjadi patologis jika tubuh tidak mampu mengkompensasi perubahan yang ada. Untuk itu perlu kita galakan pemberian kalsium kepada ibu hamil, sehingga dapat mencegah dari hal yang bisa berdampak bauruk bagi ibu dan janin. 


\section{KESIMPULAN}

Pemberian tablet kalsium pada ibu hamil dapat menurunkan hingga 4 kali resiko terjadinya hipertensi dalam kehamilan .

\section{DAFTAR PUSTAKA}

Apriani, A. et al. (2018) 'GIZI TERHADAP KADAR KALSIUM DARAH' $^{\prime}, \mathrm{II}(4)$, pp. 244-249.

Ayele, G. (2016) 'Factors Associated with Hypertension during Pregnancy in Derashie Woreda South Ethiopia, Case Control', 24, pp. 207-213.

Cunningham, F. G. et al. (2012) Obstetri Williams. Jakarta: ECG.

Dahniarti, D., Idris, I. and Am, N. (2018) 'Pengaruh Kepatuhan Suplementasi Tablet Kalsium Modifikasi Terhadap Kadar Kalsium dan Tekanan Darah Pada Ibu Hamil The Effect Of Compliance Calcium Supplementation modification Tablet On Calcium and Blood Pressure In Pregnant Women', 6.

Desi, L. et al. (2017) 'JURNAL ILMIAH KOHESI ISSN : 2579-5872 JURNAL ILMIAH KOHESI ISSN : 2579-5872', 1(3).

Fantin, F. et al. (2019) 'The importance of nutrition in hypertension', Nutrients, 11(10), pp. 10-12. doi: $10.3390 /$ nu11102542.

Gabriela Cormick, Agustín Ciapponi, María Luisa Caerata, J. M. B. (2015) 'Calcium supplementation for prevention of primary hypertension (Review)'. doi: 10.1002/14651858.CD010037.pu b2.Copyright.

Hofmeyr, G. J. et al. (2019) 'Calcium supplementation commencing before or early in pregnancy, for preventing hypertensive disorders of pregnancy', The Cochrane database of systematic reviews, 9, p. CD011192. doi: 10.1002/14651858.CD011192.pu b3.

Hofmeyr, G. J., Belizán, J. M. and Von Dadelszen, P. (2014) 'Low-dose calcium supplementation for preventing pre-eclampsia: A systematic review and commentary', BJOG: An International Journal of Obstetrics and Gynaecology, 121(8), pp. 951-957. doi: 10.1111/14710528.12613.

Kyozuka, H. et al. (2020) 'Association between pre-pregnancy calcium intake and hypertensive disorders during the first pregnancy: The Japan environment and children's study', BMC Pregnancy and Childbirth. BMC Pregnancy and Childbirth, 20(1), pp. 1-8. doi: 10.1186/s12884-020-03108-2.

Palareti, G. et al. (2016) 'Comparison between different D-Dimer cutoff values to assess the individual risk of recurrent venous thromboembolism: Analysis of results obtained in the DULCIS study', International Journal of Laboratory Hematology, 38(1), pp. 42-49. doi: 10.1111/ijlh.12426.

Parikh, N. I. et al. (2017) 'Association of Pregnancy Complications and Characteristics With Future Risk of Elevated Blood Pressure The Västerbotten Intervention Program', pp. 1-10. doi: 10.1161/HYPERTENSIONAHA. 116 .08121 .

Resnick, L. M. (1998) 'The Role of Dietary Calcium in Hypertension', 7061(98), pp. 99-112.

Schoenaker, D. A. J. M., SoedamahMuthu, S. S. and Mishra, G. D. (2014) 'The association between dietary factors and gestational hypertension and pre-eclampsia: A systematic review and metaanalysis of observational studies', BMC Medicine, 12(1), pp. 1-18. doi: 10.1186/s12916-014-01577.

Tanzil, S. (2013) 'Rasionalitas Penggunaan Antagonis Kalsium Pada Wanita Hamil Hipertensi tetap merupakan masalah kesehatan masyarakat meskipun obatnya sistolik mencapai 140 $\mathrm{mmHg}$ atau lebih dan puluh kehamilan dan berhubungan 
Received: 10 Agustus 2020 :: Accepted: 09 Oktober 2020 :: Published: 31 Oktober 2020

dengan janin, yang meliputi berat badan lahir $\mathrm{T}^{\prime}, 5(2)$, $\mathrm{pp}$. 72-80.

Tesfaye, A., Gudeta, T. A. and Regassa, T. M. (no date) 'Pregnancy Induced Hypertension and Associated Factors among Women Attending Delivery Service at Mizan-Tepi University Teaching Hospital, Tepi General Hospital and Gebretsadik Shawo Hospital , Southwest, Ethiopia'.

Villa-Etchegoyen, C. et al. (2019) 'Mechanisms involved in the relationship between low calcium intake and high blood pressure', Nutrients, 11(5), pp. 1-16. doi: $10.3390 /$ nu11051112. 